\title{
WIND CHARACTERISTICS ANALYSIS IN SOUTH LAMPUNG INDONESIA
}

\author{
Rico Aditia Prahmana ${ }^{1 * \#}$, Mahardika Yoga Darmawan ${ }^{2 *}$, Hadi Teguh Yudistira $^{1 \#}$, M. Samsul Anrokhi ${ }^{2}$ \\ ${ }^{1}$ Mechanical Engineering Department, Institut Teknologi Sumatera, Lampung Selatan, Lampung \\ Indonesia \\ ${ }^{2}$ Physics Department, Institut Teknologi Sumatera, Lampung Selatan, Lampung Indonesia \\ Equal contribution
}

\begin{abstract}
Many researchers have begun to evaluate the characteristics of the wind to be the mainstay of energy utilization for power generation. Various countries have started to conduct research to analyzethe characteristics of wind potential in certain areas. In this study, wind speed data is be measured in the South Lampung. The maximum and minimum wind speed average in one day is $2.2 \mathrm{~m} / \mathrm{s}$ (from east to west direction) and $0.5 \mathrm{~m} / \mathrm{s}$ (from west to east direction), respectively. The sensor of wind speed is located at 10 meter height from ground. The results show that the maximum wind speed can reach $3 \mathrm{~m} / \mathrm{s}$ at a height of $10 \mathrm{~m}$ on August and December. Moreover, the most wind direction during July to December goes to WSW (West SouthernWest) and SSE (South Southern East).
\end{abstract}

Keyword: wind speed, wind direction, wind speed average, power generation

\section{Introduction}

Today, many people have paid attention to renewable energy as a clean and sustainable energy source. Wind is one of the renewable energy potentials that are noticed by countries such as China [1], Iran [2], Jordan [3], Turkey [4,5] and so on. Indonesia has good potential to utilize of wind power as energy source especially in coastal area with approximately the wind speed between 2 to $6 \mathrm{~m} / \mathrm{s}$. This wind speed is suitable for small and medium scale power generations for (10 kw) and (10-100 $\mathrm{kw})$ respectively [6,7]. The wind can be felt in several locations every day, therefore many people want to use this wind as an energy source.

Many researchers began to study the characteristics of wind potential in different regions of the world. Dabbaghiyan [2] et al evaluated wind potential in Iran especially in Bushehr Province. They evaluated the wind potential at four points of the location of Bushehr province: Asaluyeh, Bordkhun, Delvar and Haft-Chah. From the wind speed data obtained, Busher province has an average wind energy power density of $265 \mathrm{~W} / \mathrm{m} 2$ per year for a height of $40 \mathrm{~m}$ [2]. They also found that the density of wind energy is different at every altitude. Sarkodie et al [8] studied the wind potential and also its economic analysis in Ghana. They didnot only analysis the potential of the wind, but also estimating the potential development of the business sector in an area based on wind potential. From various studies, the study of wind characteristic is the most important activity in the development of knowledge of the area, especially related to the utilization of wind energy.

The result of wind assessment characteristics is needed in subsequent research such as wind turbine design determination, propeller model used, material selection for propellers can even be used as regional industrial development planning. The profile of wind characteristics based on altitude will have different profiles depending to the condition of the area overlay. Therefore each region will have specific wind potential characteristics so that this research is needed.

In this study the main purpose is to understanding the characteristics of wind potential in the South Lampung. The assessment of wind potential characteristic can be used for further research such as for the design of used wind turbine, propeller model, material used which has been described in the background.

\section{Theory}


The Weibull distribution is used to predict wind speed and wind direction accurately. Wind data is used to obtain average wind speed and direction in an area and statistical models can be used to generate statistics from wind data. Making averages out of wind data to overcome data or system losses, measurement errors and more. This is based on the Weibull distribution as shown in the equation below.

$$
\begin{gathered}
F(u)=1-\exp \left[-\left(\frac{u}{A^{\prime}}\right)^{k}\right] \\
f(u)=F^{\prime}(u)=\frac{k}{A}\left[\frac{u}{A}\right]^{k-1} \exp \left[-\left[\frac{u}{A}\right]^{k}\right] \\
a_{v}=\int f(u) u^{v} d u=A^{v} \cdot \Gamma\left[1+\frac{v}{k}\right] \\
\mu=a_{1}=A \cdot \Gamma\left[1+\frac{1}{k}\right]
\end{gathered}
$$

Where $k$ is the Weibull parameter, $A$ is the Weibull parameter scale, $f(u)$ is the Weibull density function, $F(u)$ is the Weibull cumulative distribution function, is statistical moment and $\mu$ is the average wind speed.

\section{Data and Analysis}

The data set was obtained from BMKG (Meteorological climatology and geophysics Bureau) Station, in Branti south Lampung. The data recorded is set in one day average wind speed/direction at the height of $10 \mathrm{~m}$. The instrument used to measure the wind data are wind cup and wind vane. Location of the instrument is in Latitude $5^{\circ} 14^{\prime} 39.18^{\prime \prime S}$ and Longitude $105^{\circ} 10^{\prime} 47.39^{\prime \prime} \mathrm{E}$.

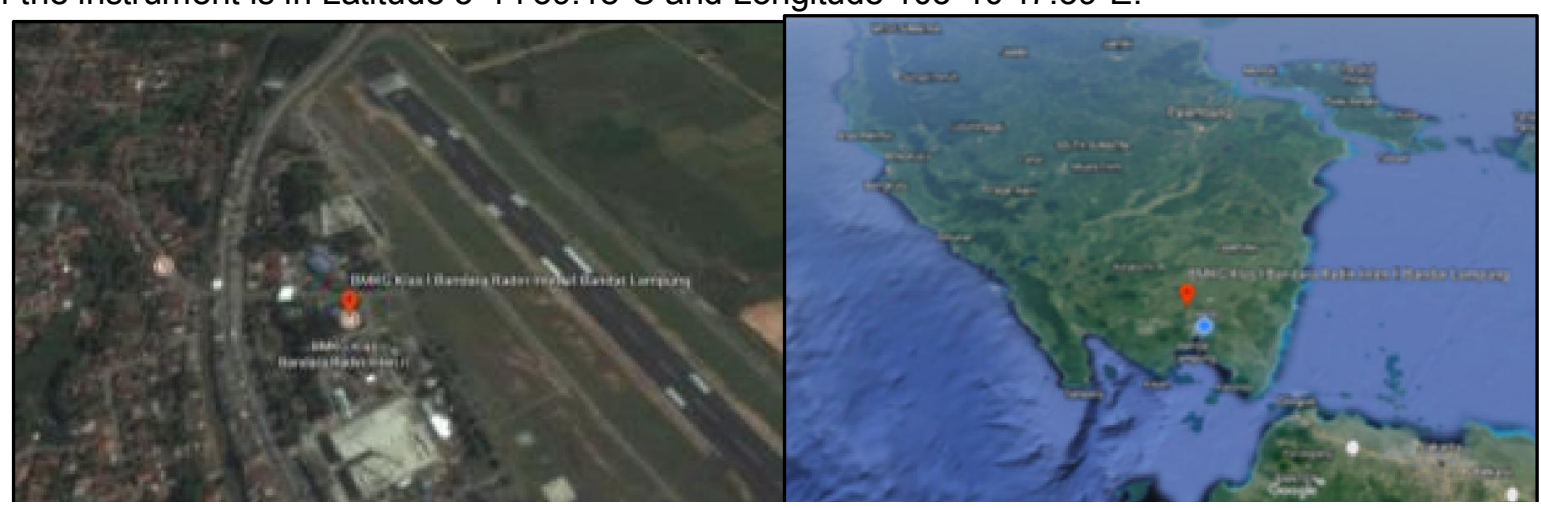

Figure 1. Location of BMKG Branti South Lampung

Figure 2 shows wind speed during July to December with average wind speed about $1.4 \mathrm{~m} / \mathrm{s}$. and the peak of wind speed average could reach $3 \mathrm{~m} / \mathrm{s}$ on August and December 2016 and this happen may due extreme weather condition. 


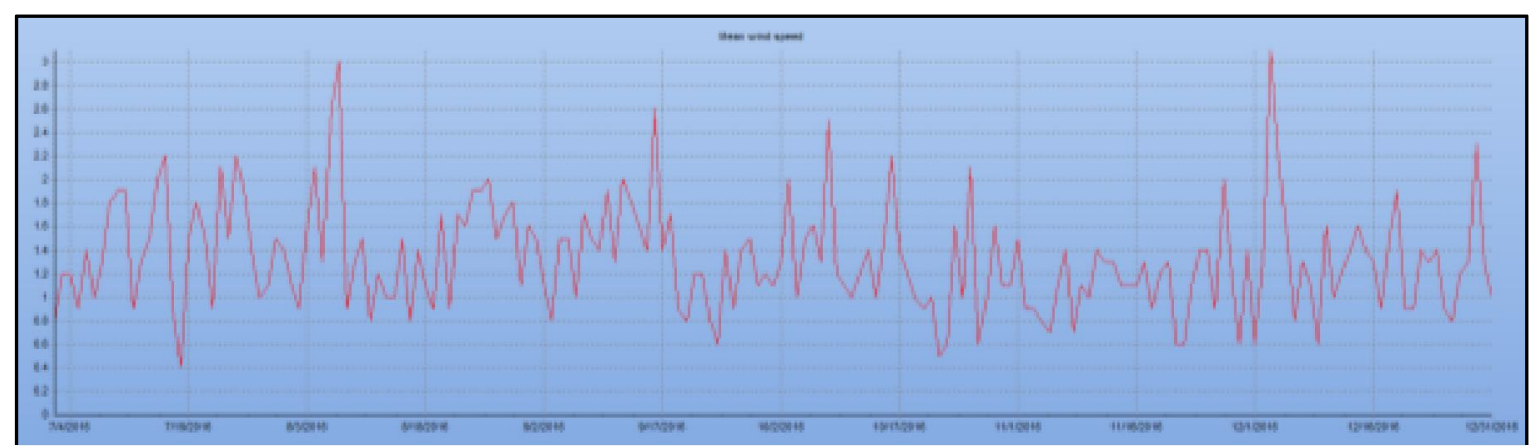

Figure 2. Wind speed average from July to December 2016

Figure 3 and figure 4 shows wind direction during July to December dominant to WSW (West Southern West) and SSE(South Southern East), in July the wind direction came from the south to the north, then in august and September wind direction goes to northeast, in October wind direction goes to NNW (North Northern West) and SSE (South Southern East), and then in November and December West and WSW (West Southern West).

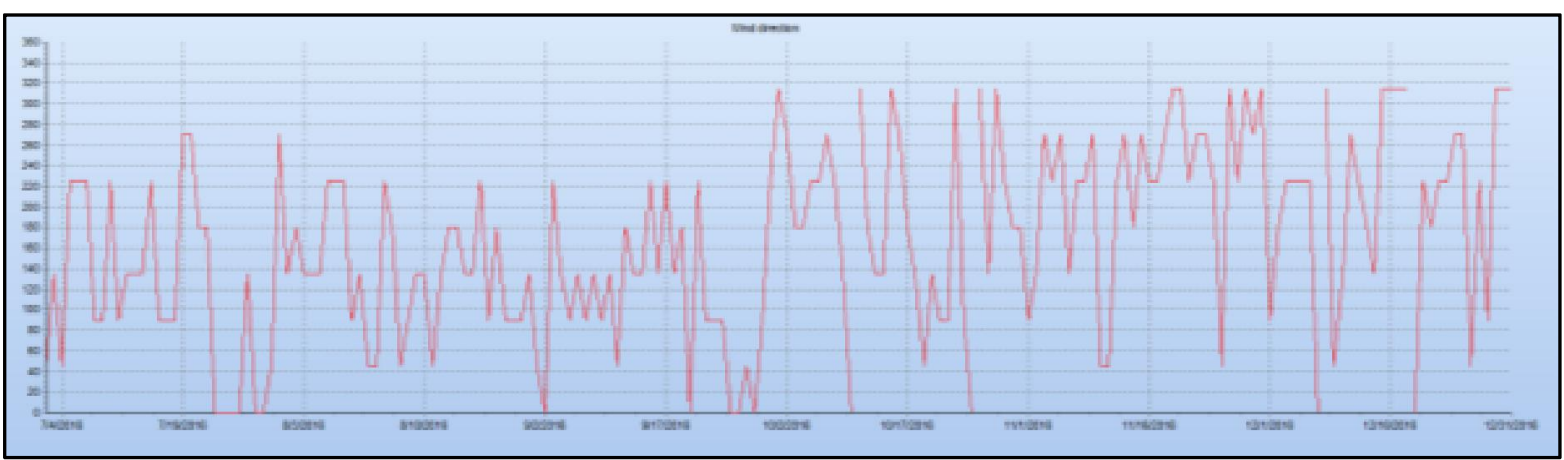

Figure 3. Wind direction average from July to December 2016
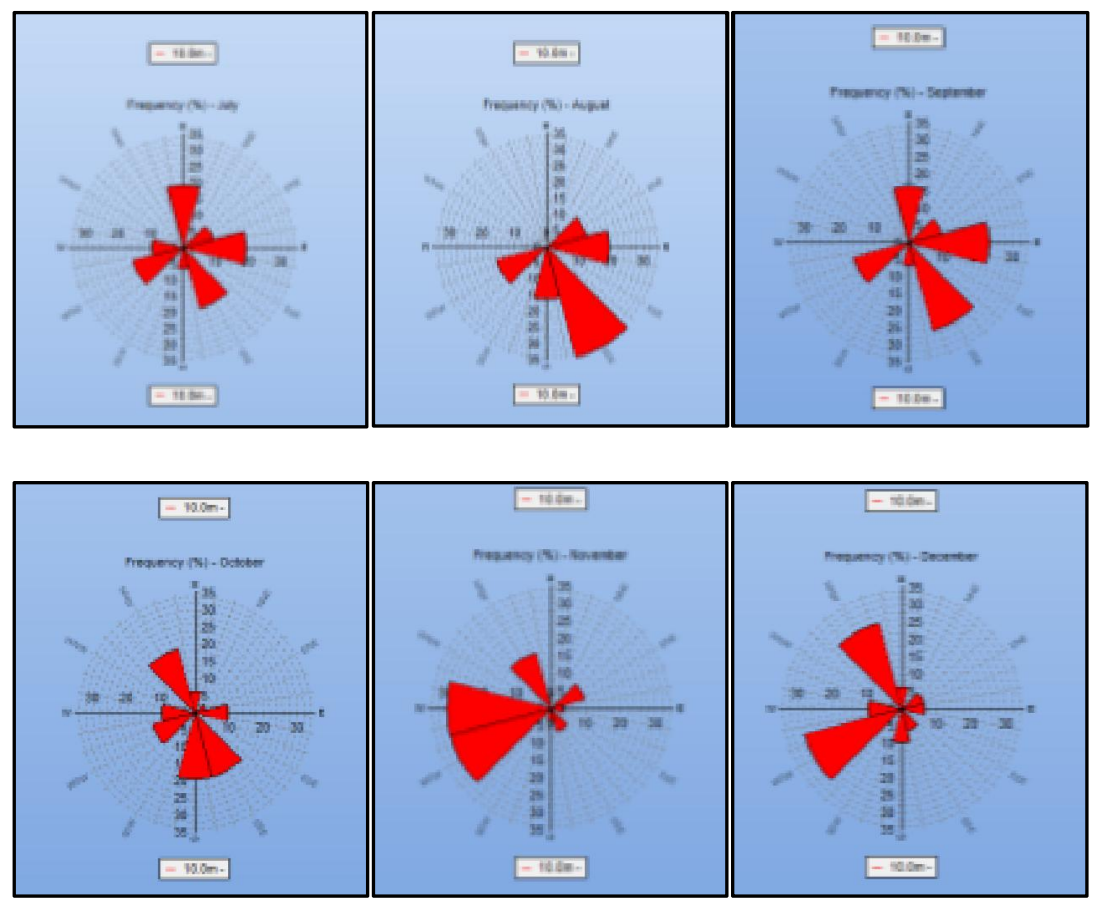

Figure 4. Wind Rose distribution from July to December 2016 
Figure 5 shows Weibull distribution from July to December, it's known that $76 \%$ of average wind speed measured during the period of July to December is $1.4 \mathrm{~m} / \mathrm{s}$.its means the strongest wind speed appears during these months period.

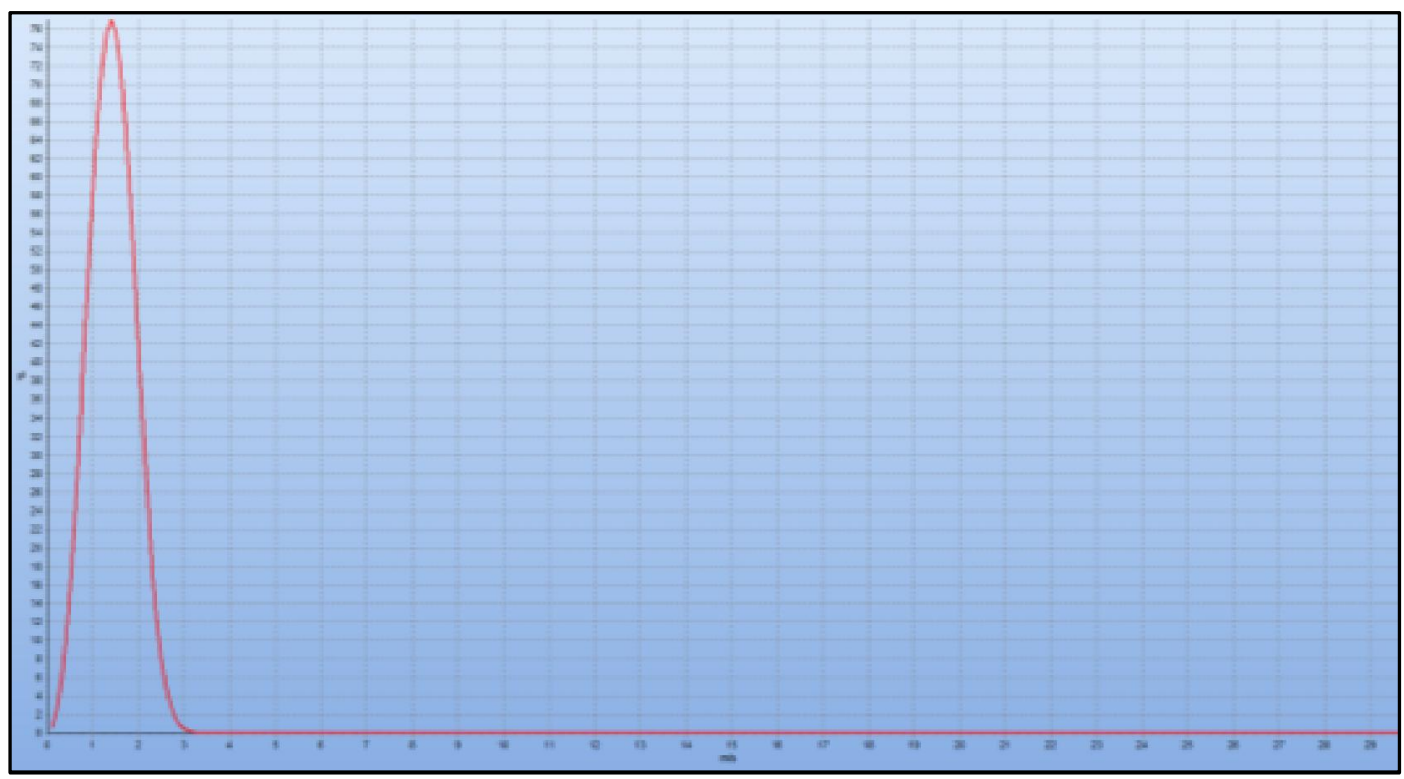

Figure 5. Weibull distribution from July to December 2016

\section{Conclusion}

The results show that the maximum wind speed can reach $3 \mathrm{~m} / \mathrm{s}$ at a height of $10 \mathrm{~m}$ on August and December. Moreover, the most wind direction during July to December goes to WSW (West Southern West) and SSE (South Southern East). In future studies, the measure of wind data will be performed at different locations in South Lampung in order to repeat the same experiments. It is expected that the results presented in this study will be of interest to wind turbine designers in Indonesia in particular and around the world in general.

\section{Acknowledgments}

We would like thank to Institut Teknologi Sumatera for research funding through LP3 ITERA.

\section{Reference}

[1] L. Hong and B. Möller, "Offshore wind energy potential in China: under technical, spatial and economic constraints," Energy, vol. 36, pp. 4482-4491, 2011.

[2] A. Dabbaghiyan, et al., "Evaluation of wind energy potential in province of Bushehr, Iran," Renewable and Sustainable Energy Reviews, vol. 55, pp. 455-466, 2016.

[3] K. M. Bataineh and D. Dalalah, "Assessment of wind energy potential for selected areas in Jordan," Renewable energy, vol. 59, pp. 75-81, 2013.

[4] C. Ilkilic, "Wind energy and assessment of wind energy potential in Turkey," Renewable and Sustainable Energy Reviews, vol. 16, pp. 1165-1173, 2012.

[5] Ozerdem, B., Turkeli, H. M., "Wind energy potential estimation and micrositting on Izmir Institute of Technology Campus, Turkey," Renewable Energy, Vol. 30, p. 1623-1633, 2005.

[6] M.H. Hasan et al, "A review on energy scenario and sustainable energy in Indonesia,"Renewable and Sustainable Energy Reviews, vol.16, pp. 2316- 2328, 2012.

[7] Indonesia energy outlook \& statistic 2006. Depok, Indonesia: Energy Reviewer, University of Indonesia; 2006.

[8] S. Asumadu-Sarkodie and P. A. Owusu, "The potential and economic viability of wind farms in Ghana," Energy sources, Part A: Recovery, utilization, and environmental effects, vol. 38, pp. 695701, 2016. 